\title{
CONSTRUCTION TECHNOLOGY OF OPEN GRANITE STONE CURTAIN WALL
}

\author{
Wang XiaOYAN ${ }^{1,2}$, LAI P.C ${ }^{1 *}$, \\ YU YABIN ${ }^{3}$ \\ ${ }^{I}$ Tun Abdul Razak University, Malaysia \\ ${ }^{2}$ Guangzhou City Construction College, Guangzhou, China \\ ${ }^{3}$ Guangdong Urban Planning Construction Supervision Co., Ltd., Guangzhou, China \\ *Corresponding author: researchpc3@gmail.com
}

(Received: 24 December 2021; Accepted: 18 February 2022; Published on-line: 01 July 2022)

\begin{abstract}
This paper developed the self-locking back bolt fastener and the open stone curtain wall with waterproof function aimed for installation accuracy, connection structure stability, waterproof leakage, and earthquake resistance in constructing open granite stone curtain walls. The practice shows that applying this construction technology improves the stability and seismic performance of the curtain wall connection structure while also ensuring the stone curtain wall's waterproof and decorative properties.
\end{abstract}

KEYWORDS: strip grid stone, staggered I-shaped stone, stone curtain wall, construction technology.

\section{INTRODUCTION}

In recent years, as the construction industry has advanced technologically, people's expectations for the effect of exterior decoration have risen. As a natural material, stone curtain walls are strong and durable, noble and elegant, and resistant to freezing. They are widely used to decorate building façades.

While the stone curtain wall has the advantage of a beautiful shape and various colors, the curtain wall connection's reliability and waterproof performance are relatively high, and construction is difficult. As a result, it has attracted the attention of numerous scholars who have researched the stone curtain wall's construction technology.

Liu Weixiong and Zhang Yong analyzed the waterproof design and application of stone curtain wall joints. They verified the design points in the waterproof design to improve the waterproof design's application performance [1-2]. Wang Zuohu researched the strength of the connection between the stone curtain wall and the connector [3]. Yu Huaxin investigated four different installing the back-trough curtain wall connection technology [4]. Liu Yuanxin conducted research and development on the curtain wall's corner connector and realized the stable installation of the corner structure of the curtain wall [5]. Li Changqiu drew his interpretation of the construction process of the back-bolted dry-hanging stone (open) curtain wall from the Shengli Stele Curtain Wall Project in Jiujiang City [6]. Chen Zhifeng, Su Ying, Xue Guang, and Wang Linbo analyzed the critical points in the application process of stone curtain wall construction technology and quality control [7-10]. Therefore, this paper developed the self-locking back bolt fastener and the open stone curtain wall with a waterproof function. 


\section{CASE STUDY}

\subsection{Project Overview}

The curtain wall project for a city's science and innovation center comprises six organically buildings. The total area covered by the construction is $73,979.97$ square meters. The building's main cornice measures 29.7 meters in height. The structure consists of six stories above ground and one underground. The facade is primarily decorated with glass curtain wall systems, stone curtain wall systems, and aluminum. There is an extensive open granite stone curtain wall system on the south and a portion of the north of Buildings 1-5, and a stone grille curtain wall on a portion of each building's facade, as illustrated in Fig. 1. The stone curtain wall steel keel is made of Q235B material. The main keel is $120 \mathrm{~mm} \times 60 \mathrm{~mm} \times 5 \mathrm{~mm}$ galvanized steel square pass. The secondary keel is $63 \mathrm{~mm} \times 63 \mathrm{~mm} \times 5 \mathrm{~mm}$ galvanized angle steel, the main and secondary keels are welded, the surface material is $30 \mathrm{~mm}$ thick, and dark combined granite stone. This project's granite stone curtain wall installation requires high precision, strong stability, and high waterproof requirements, and the construction workload is large. The curtain wall construction link has a significant impact on the quality of the entire construction project.

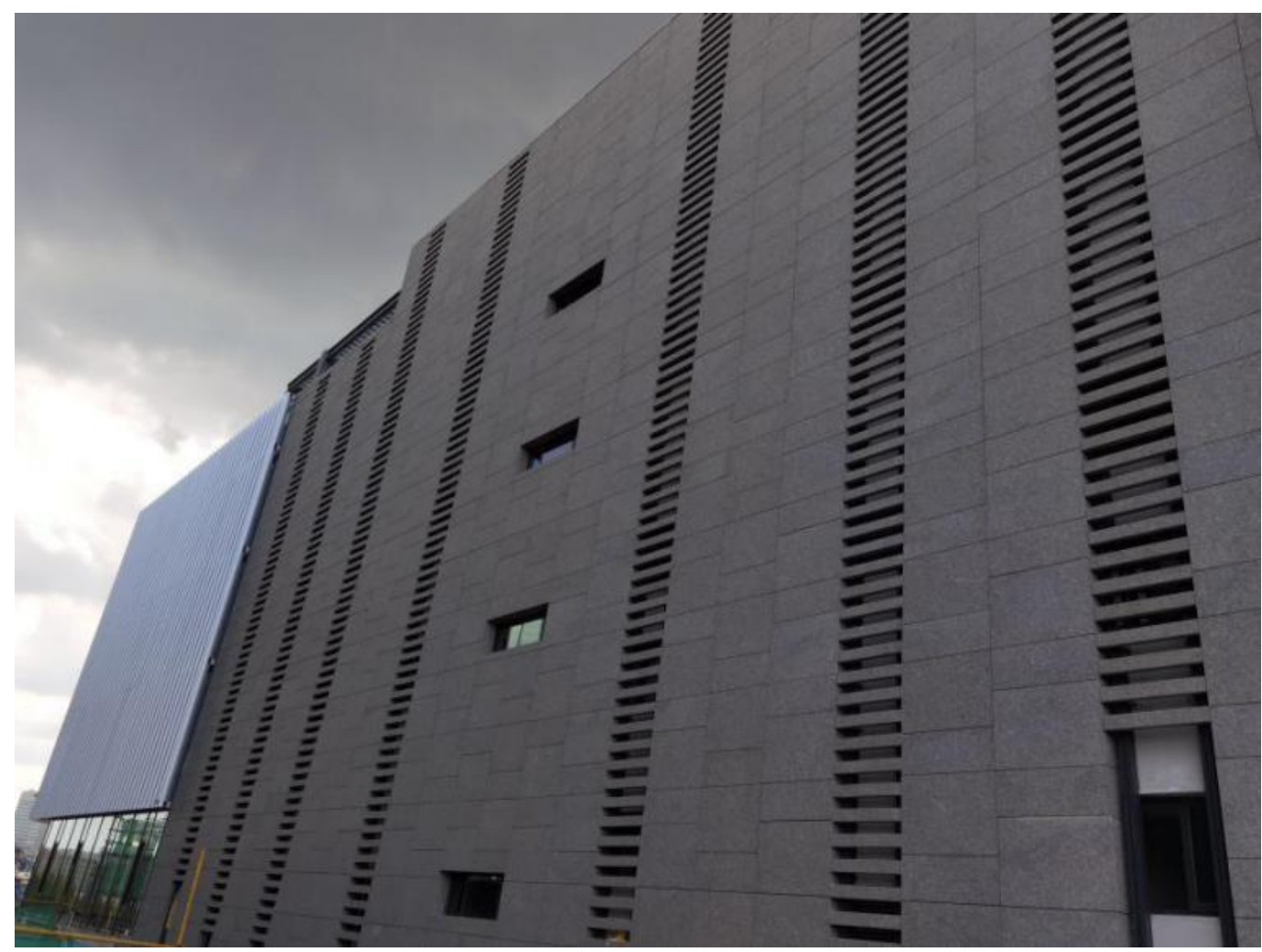

Fig. 1. The effect of stone curtain wall installation

\subsection{Construction Difficulties of Granite Stone Curtain Wall}

The stone curtain wall combines bar grille stone and staggered I-shaped stone. The strip grid stone curtain wall is made of strips and is easily damaged. Each stone needs to be installed separately, with a $150 \mathrm{~mm}$ space between them. The stone of the curtain wall is connected with the wall through the keel and the new type of back bolt. Curtain wall construction is large, plate installation accuracy is high, and quality control is challenging. Considering the impact of the project's geographical location and weather conditions on structural damage and waterproofing 
needs, the requirements for waterproofing the external wall of the building and the stability of the strip grid stone after construction are higher.

\section{RESEARCH AND DEVELOPMENT OF OPEN GRANITE STONE CURTAIN WALL CONSTRUCTION TECHNOLOGY}

\subsection{Research and Development of Self-Locking Back Bolt Fastener Connection Technology}

The stability, resistance, and waterproofing ability of stone curtain wall structures are essential for stone curtain walls to play their normal function. The quality of the connector connecting the stone curtain wall affects the quality and safety of the whole stone curtain wall. The stone curtain wall is mostly installed in a sealed manner, preventing rainwater from entering the internal structure, causing rust and other damage to keel and pendants, reducing the stable performance of pendants. Although grid format or open stone curtain walls appear to be more attractive, they have higher requirements in waterproofing, structural connection, materials, and other factors.

\subsubsection{Connection scheme of back bolt pendant}

The architectural appearance of the open modular stone curtain wall, when the strip stone grid is installed, the spacing is $150 \mathrm{~mm}$, and the spacing is open structure, which requires higher waterproof protection. Traditionally, each profile is installed with a T-shaped fastener or a back bolt attachment. In the construction process, the back bolt hanger on the back of the profile is fixed on the keel by hanging and then fixed after adjusting the gap between the horizontal and vertical joints. The gap between the stone plate is generally $5-8 \mathrm{~mm}$ and then sealed with silicone sealant. The biting part of the back bolt hanging on the keel must be as large as possible. Otherwise, the connection of the stone plate will be reduced; there is a hidden danger of falling off. The internal structure of the stone curtain wall may be affected by weather factors, which can easily damage the pendant's performance, affect the stable connection of the stone plate, and maybe loose and fall off.

\subsubsection{Research and Development of Self-Locking Back Bolt Fastener Connection Technology}

A self-locking back bolt fastener is developed to ensure the stability of a high-rise building's stone curtain wall. When installing the stone curtain wall panels, first fix the keel to the embedded steel parts on the wall, connect the back bolt aluminum alloy snap fasteners to the keel, and install an aluminum alloy protective plate outside the keel to protect the keel structure. Only the aluminum alloy female fastener is exposed on the surface. The seam between the aluminum alloy protective plate and the female fastener is sealed with silicone sealant material, as illustrated in Fig. 2 and Fig. 3. When installing, align the hole of the subfastener with the raised structure on the female fastener's bottom and push it to the left to lock it automatically. The self-locking function improves the stability and earthquake resistance of the pendant connection structure. 


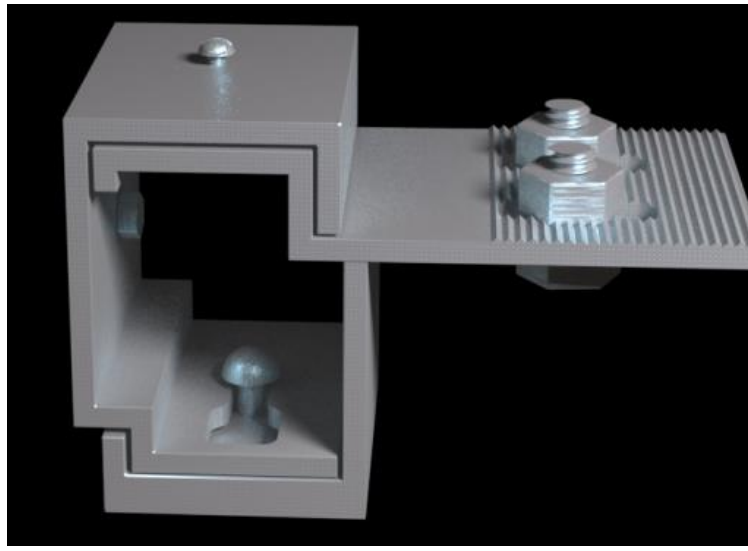

Fig. 2. 3D diagram of self-locking back fasteners

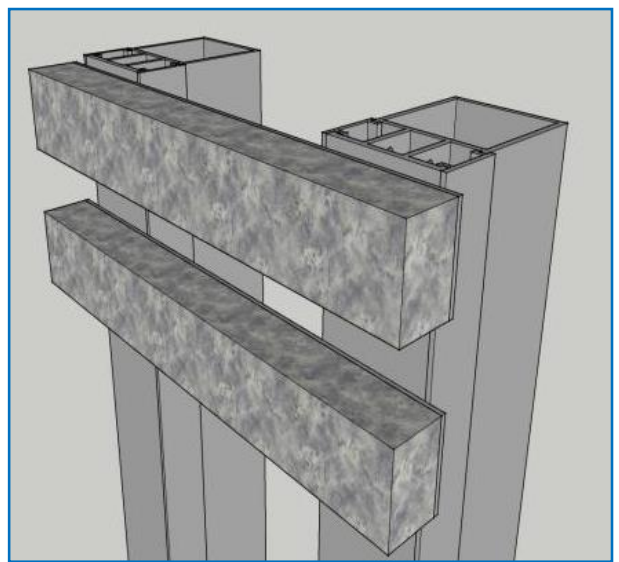

Fig. 3. The connection structure of open stone curtain wall with waterproof function

\subsection{Research and Development of Open Stone Curtain Wall Connection Structure with Waterproof Function}

The open stone curtain wall, particularly the bar grille shape, imposes stricter waterproofing requirements on the curtain wall connection structure. Therefore, the research group developed its connection structure and created a waterproof stone curtain wall. Two components comprise the connecting structure: a vertical keel and prefabricated strip stone profiles.

Vertical keel installation: The keel is made of aluminum alloy, has a concave cross-section, and is provided with openings on both sides, and the openings are covered with buckle strip covers. The function of the buckle strip cover to protect the bolts also improves the decorative effect. After installation, the structure has better waterproof and decorative functions.

Assembly-type strip stone profile installation: The fabricated strip-shaped stone profile is made from an aluminum alloy $\mathrm{C}$-shaped keel with a minimum thickness of $4 \mathrm{~mm}$. The exterior of the keel base material has adhered to the stone with structural glue. The stone and keel are then drilled with an advanced stone drilling machine, and the back bolt aluminum alloy Lshaped connector is installed with a spacing of no more than $600 \mathrm{~mm}$. An aluminum alloy plate with a buckle seals the opening surface of the c-type keel. The aluminum alloy plate's surface has been shaped into a slot to reveal the aluminum alloy L-shaped connector. As illustrated in Figure 3, the slot is sealed with silicone sealant. The L-shaped connector is inserted into the vertical keel groove during installation, and then bolts are used to penetrate the keel and the 
hole in the L-shaped connector to create a fixed connection. For each 2-meter height, the keel buckle bar lid is installed.

\subsection{Research and Development of Triple Waterproof Structure Technology for Stone Curtain Wall}

\subsubsection{Research and Development of Triple Waterproof Construction Technology}

The open combination stone curtain wall, especially the bar grille shape, has high waterproof protection requirements for the curtain wall connection structure. If only two waterproof lines of the exterior building wall are used, the overall waterproof and leakage prevention function of the building cannot meet the standard. Therefore, to ensure the open modular stone curtain wall's installation and construction quality, a three-layer waterproof structure technology combination scheme protects the exterior building wall and connecting structure layer.

Waterproof structure scheme of combined granite stone curtain wall. The waterproof structure plan of the combined stone curtain wall adopts the combination plan of "basic waterproofing of building exterior wall + protective waterproofing of structural layer + sealant caulking". First, apply two coats of waterproof paint on the plastering surface of the exterior wall of the building as the first waterproof layer. After the first layer of waterproof coating is qualified, install the vertical keel and horizontal keel of the stone curtain wall structure layer. Then, install the aluminum water baffle with waterproof protective technology on the outer surface of the structure layer. The water baffle and the connection of the baffle shall be filled with sealing glue. The water baffle is used as the second waterproof layer. After the aluminum water baffle is accepted, install the granite stone panel. After the panel is installed and fixed to a certain assembly unit, use the weather-resistant glue of the specified design to fill the joints. The glue joints need to be pressed, smoothed, and filled when injecting the glue. The seam injection glue is used as the third waterproof layer. The technical scheme can effectively protect the structural layer of the stone curtain wall.

Waterproof structure scheme of open granite stone curtain wall. The waterproof structure scheme of the open granite stone curtain wall adopts the combination scheme of "brick joint, waterproof coating + waterproof mortar + waterproof coating". First of all, paint the joints of the bricks that have been built. The paint is required to be fully painted. The treatment of the brick joints can effectively prevent rainwater from penetrating the inner wall from the brick joints. The brick joint's waterproof coating is used as the first waterproof layer. After the waterproof brick joints are qualified, use waterproof cement mortar to plaster the outer wall of the building in layers according to the bottom, middle and surface layers. When plastering, the verticality and flatness of the wall must be controlled, and the waterproof cement mortar forms the waterproof protection. The layer is the second waterproof layer. After the waterproof cement mortar is qualified, apply two waterproof coatings as the third waterproof layer on the outer wall. Finally, the strip grid is installed, and the three waterproofing can better improve the waterproof and anti-seepage effect of the outer wall of the building.

\subsubsection{Water Spraying Experiment of Open Combined Granite Stone Curtain Wall}

The water spray test needs to be carried out twice. The formal water spray test is carried out from top to bottom. All doors and windows should be closed before the test.

The first water spray test aims to inspect, find leakage, and make corrections fully. From top to bottom, hang water pipes for every 3 floors as a water spray section. The water spray test can be carried out on key parts to ensure the water spraying effect, such as the window side 
before the water spraying. The water spraying time can be determined according to the project's actual situation.

The purpose of the second water spray test is to pass a comprehensive inspection to ensure that the leakage rate of the external wall is close to zero when the building is handed over. Generally, it is carried out after the outer scaffolding is removed. The water supply branch pipe is left as a watering section on the 6th floor. The water volume and pressure adjustment control valve is set on the water supply branch pipe. Before sprinkling, fix the hanging sprinkler pipe in advance and park it at the sprinkling position. After healing, connect the sprinkler pipe with the water supply branch pipe to prepare for sprinkling. When the sprinkler pipe is long, multiple water supply branch pipes should be evenly arranged along the outer wall to ensure that the water pressure at the farthest sprinkler point is generally not less than $0.1 \mathrm{MPa}$.

When spraying water, adjust the size of the control valve according to the water volume and pressure of the spray pipe. Generally, the water pressure at the farthest watering point should not be less than $0.1 \mathrm{MPa}$, and the pressure should not be greater than $0.6 \mathrm{MPa}$.

The first continuous spraying time should be no less than $24 \mathrm{~h}$; it must be fully carried out and cannot be interrupted or exempted by rain. If there is leakage, it should be rectified, and the spraying time after rectification should be no less than $12 \mathrm{~h}$ and not more than 24 hours.

After each water spray test, the construction unit, supervision unit, external window installation unit, and external wall construction unit technicians shall jointly inspect the external walls and external windows and form inspection records for future reference.

The duration of the second full showering shall not be less than 12 hours and not more than 24 hours. The full water spraying must also be carried out uninterruptedly, and the test cannot be interrupted due to rain or other reasons. Suppose there is a leakage problem after the second full spraying. In that case, it needs to continue to rectify and spray the water until the average household leakage rate according to the unit project statistics is not more than 0.1 points/household, the spraying test work is over.

\section{CONSTRUCTION PROCESS AND OPERATION POINTS}

The process and operation points are as follow (Fig. 4):

- BIM deepening design: Based on the curtain wall node diagram, create a BIM threedimensional model, conduct collision inspections on curtain walls, support steel structures and other related disciplines, quickly discover problems, and coordinate solutions. Deepen the design of the curtain wall panels according to the model, and classify the facades according to the different surface materials of the curtain wall. Special sizes need to be numbered. The model can directly export the material processing drawings and interface with the processing plant for blanking processing.

- Panel grouping and classification number: Strictly control the color difference, size deviation, and stone damage. The stone shall not be used if there is obvious color difference, damage, chipping, cracks, corners, etc. The color and pattern of the stone slab are coordinated, and the qualified stone slabs are numbered and classified according to the drawings. First, divide 1-6 buildings into 6 groups with different construction scopes. Rectangular panels, strip panels, and irregular panels are classified, and then only panels with the same ruler and different rulers are numbered. 


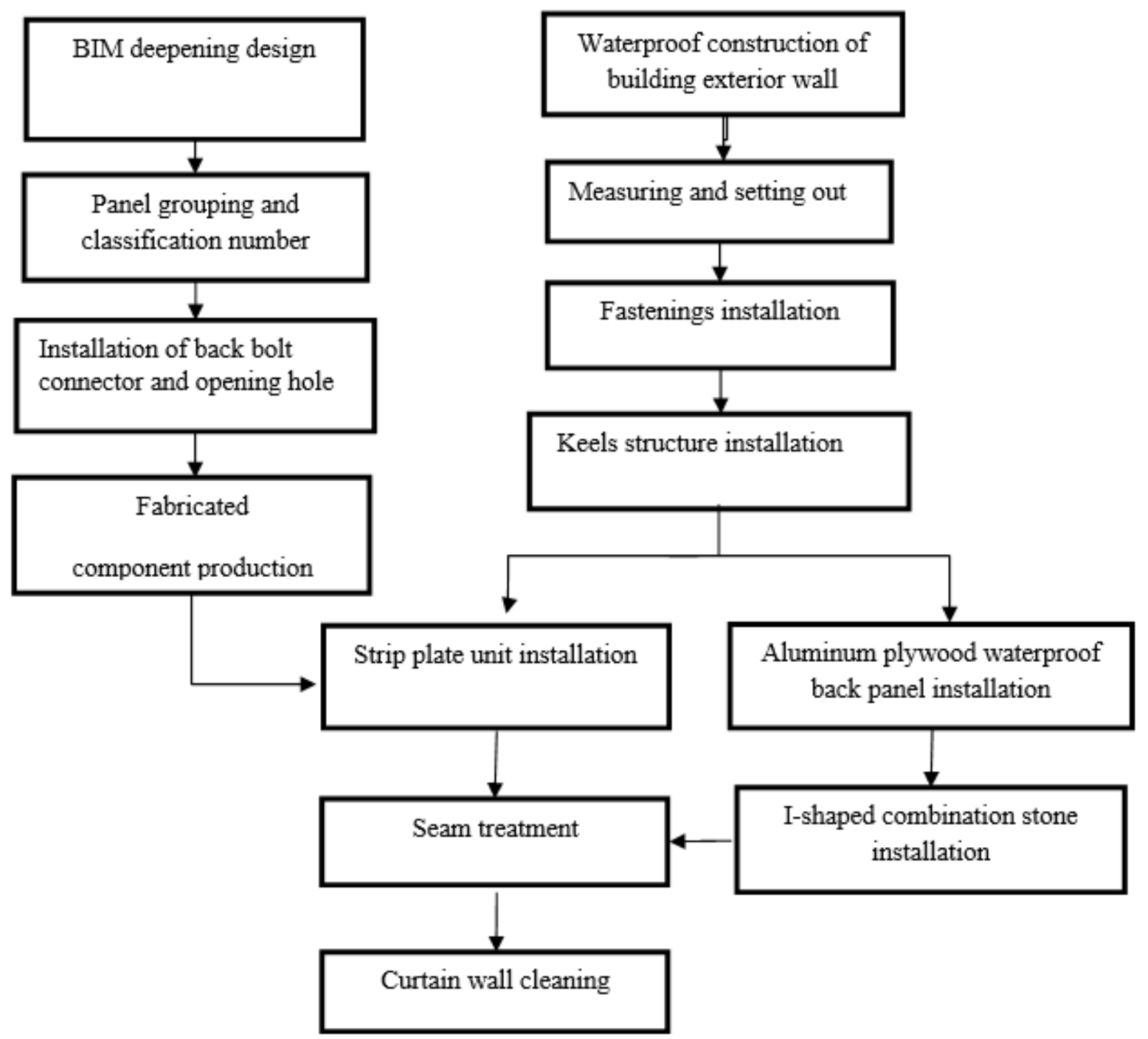

Fig. 4. Construction process flow chart of open combined stone curtain wall

- Installation of back bolt connector and opening hole : Use special stone back bolt drilling equipment to make holes in the stone slab, and grind the holes on the upper and lower sides of the back of the stone slab. The distance between the holes is $100 \mathrm{~mm}$ to $180 \mathrm{~mm}$ from the edge, and the horizontal distance should not be greater than $600 \mathrm{~mm}$. When installing the back bolt, determine the fastening method of the back bolt implantation according to the type of the back bolt. For the non-rotating type back bolt, use special tools to expand (pull) the expansion tube end and tighten it ; Screw-in back the bolt, screw in the bolt to expand, and tighten the expansion tube end. Adding a nylon mesh cover on the surface of the back bolt improves the seismic performance of the back bolt hanger, eliminates the hard contact between the back bolt and the stone slab, and reduces the effect of thermal expansion and contraction. Stone slab hole forming process: use special equipment to grind columnar holes $\rightarrow$ expand holes $\rightarrow$ clear holes. Installation of back bolt connector: Place the workbench (place a suitable rubber plate on the table), $\rightarrow$ place the holed stone plate $\rightarrow$, implant the back bolt into the hole of the stone plate $\rightarrow$ complete the back bolt fastening $\rightarrow$ component pull-out test.

- Fabricated component production : According to the hole-forming technology and requirements of the stone slab, make holes for the stripped stone and fix it on the keel with structural glue. The holes of the keel should be consistent with the stone. Then install the back 
bolt connector, install the gusset plate, and fill in the sealant at the intersection of the back bolt connector and the gusset plate.

- Waterproof construction of building exterior wall : For the open grid-shaped parts, the building exterior wall waterproofing adopts the process of "brick joint, waterproof coating + waterproof mortar + waterproof coating" to ensure that the base layer of the building does not seep.

- Measuring and setting out: Accurately locate the main structure's benchmark axis and level point, check the corner position, axis position, and height section of the wall against the curtain wall construction drawing to ensure the accuracy of line winding.

- Fastening's installation: The connecting piece and the embedded piece are connected by welding. If there are embedding plate deviations, it needs to be processed according to the design requirements. If there is no embedding plate, it needs to be post-embedded (the postembedded parts are connected to the concrete structural wall by planting chemical bolts) to ensure safety and meet the relevant specifications. Install at least three adjacent vertical materials on the connecting piece, level the connecting piece, and pay attention to the leveling of the adjacent vertical material (the leveling of the skeleton can be adjusted by the adjusting hole of the connecting piece). The welding quality, weld height, and welding safety shall be ensured during welding, and the welding slag shall be removed in time and submitted for inspection. After the acceptance is passed, anti-corrosion treatment is required. That is, the anti-corrosion paint is painted.

- Keel structure installation: Layout the line according to the construction drawing and install the mullion. Lead the construction level control line to the mullion and check it with a level ruler. Install the metal beams according to the design dimensions. The beam is perpendicular to the mullion. Before welding, the lower and adjacent completed working surfaces should be protected; symmetrical welding should be used to reduce the deformation caused by welding. After the weld quality has passed the inspection, all the welds and welds shall be removed from the welding slag and painted with anti-rust paint. The curtain wall lightning protection device must be effectively connected to the main structure lightning protection device according to the design and related standards.

- Installation of strip plate unit for open stone curtain wall: After the keel structure is installed, the assembled strip plate units will be installed in order from top to bottom and from left to right. First, install the leather strip-type panel unit on the top floor according to the baseline of the curtain wall. After installing each floor, the verticality error needs to be adjusted and accumulated. Install the keel snap strip cover every time the height of the strip plate unit of 2 meters is installed.

- Installation of aluminum alloy waterproof backboard for combined stone curtain wall: After the keel structure is accurately positioned, the aluminum alloy back bolt transverse frame is fixed to the surface of the structural keel with bolts, which can be completely sealed, not only to keep the internal and external pressure of the stone, but also to prevent rain splashing, and keep the rain out while ensuring the quality of the appearance.

- Combined stone curtain wall I-shaped stone installation: First of all, positioning marking, determine the horizontal and vertical position of the stone plate, and in the frame plane peripheral control point, pull control line control installation flatness and the position of each component, selected stone plate specifications, according to the serial number of the installation of the stone plate. When installing, lift the stone steadily, align the back bolt fastener with the fixed back bolt hanger groove, push the stone plate to the right to lock 
automatically. Adjust the fine-tuning screw to correct the flatness of the stone plate so that the plates are in the same plane between each other.

- Seam treatment: After the granite plate panel is installed and a certain assembly unit is completed, the joint filling and glue injection process can be carried out. First, the joint filling part shall be purified with the specified solvent after being inserted into the foam rod. The stone on both sides of the plastic joint shall be affixed with the wrinkled paper, and then the specified brand of resistant rubber shall be used for filling the joint. Glue injection will be pressed, smooth. After filling the glue, tear off the wrinkled paper and clean the stone surface.

- Curtain wall cleaning: After construction, clean the stone wall with water and a special cleaning agent, and carry out protective agent construction as required

\section{CONCLUSION}

The construction and installation of the stone curtain wall of this project use the selflocking back bolt fastener connection technology. The waterproof open stone curtain wall connection structure, wh The waterproof protection performance is better, the wind resistance and earthquake resistance are high, and the assembly construction method is faster, which is a better optimization and improvement plan. It has achieved certain results in design and construction technology and construction management, solved the technical difficulties of the open combined stone curtain wall, improved the engineering quality of the stone curtain wall construction, and shortened the construction period.

During the stone curtain wall construction and installation process, the treatment of the curtain wall joints, the firmness of the connection, and the waterproof performance of the stone curtain wall will affect the overall construction quality of the stone curtain wall. This technique is used in engineering to solve the technical problems in the stone curtain wall construction process. Further studies are encouraged in the areas of stone curtain wall innovation and further development continues to work on potential patented technologies from the above points.

\section{ACKNOWLEDGEMENT}

This project is with the support of China Civil Engineering Group Co., Ltd., Chief Engineer Huang Jing for providing engineering cases and suggestions during the writing process.

\section{REFERENCES}

[1] Liu Weixiong. Exploration of Waterproof Design and Application of Stone Curtain Wall Seam Channel. Journal Technology Wind, 2012 (06): 82.

[2] Zhang Yong. Haidian North Cultural Center Project Curtain Wall Waterproof Design. Journal China Building Waterproof, 2018 (05): 32-36.

[3] Wang Zuohu, Gao Zhanuang, Pan Yongguang, Yao Yuan, Li Luowei. Progress on Connection Strength Between Stone Curtain Wall and Connectors. Journal Sichuan Architectural Science Research, 2019,45 (03): 1-4.

[4] Yu Huaxin, Hou Jianqun. Backgroove Curtain Wall Connection Technology. Journal Construction Technology, 2010,41 (10): 929-931.

[5] Xu Yong, Wen Chang, Shu Bo, Peng Dekun, Zhu Feidong. Construction Technology of Heterogeneous Curtain Wall System of a Large Venue. Journal Building structure, 2020,50 (09): $110-115$.

[6] Li Changqiu. Application of Backbolt Dry Hanging Stone (Open) Construction Technology in Jiujiang Shengli Monument Curtain Wall Project. Journal Engineering Quality, 2008 (22): 4043. 
[7] Chen Zhifeng. Key Technical Points and Quality Control Of Stone Curtain Wall Engineering. Journal Jiangxi Building Materials, 2021 (05): 137-138.

[8] Su Ying. The Key Points of Stone Curtain Wall Construction Quality Control. Journal China Building Metal Structure, 2021 (10): 58-60.

[9] Xue Guang, Liu Zhipeng, pastoral. Technical Control Standard and Key Construction Points of Stone Curtain Wall Construction. Journal Sichuan Building Materials, 2021,47 (10): 109-111.

[10] Wang Linbo. Research on Stone Dry Hanging Construction Technology in Building Curtain wall construction. Journal Smart City, 2021,7 (14): 127-128. 